\title{
Uso de celular no ensino de ciências exatas: um estudo de caso
}

\author{
Use of cell phone in the exact sciences teaching: a case study
}

\author{
Jairo Savio Ramos de Medeiros ${ }^{1}$ \\ Henrique Duarte da Fonseca Filho ${ }^{2}$ \\ Robert Saraiva Matos ${ }^{3}$
}

\begin{abstract}
RESUMO: Este artigo apresenta um estudo de caso realizado em duas escolas públicas, com objetivo de estudar a aceitabilidade de estudantes e professores sobre o uso de aparelhos móveis no ensino de ciências exatas. As escolas foram escolhidas, aleatoriamente, na cidade de Macapá, Estado do Amapá e dois questionários estruturados foram aplicados para coletar dados, com três professores e duzentos e trinta estudantes do ensino médio. Os resultados mostraram que as respostas dos estudantes convergem sobre o uso do aparelho para fins educativos, mesmo havendo alguma divergência. Além disso, os professores apresentaram visão divergente sobre o uso destas tecnologias no contexto escolar. Quando comparados os dados, verificamos que os alunos pensam de forma semelhante, quanto ao aproveitamento dos celulares para o ensino, cujos testes $T$ de Student apresentaram valores $p>0.05$ ou $p>0.01$. Assim, independentemente da escola, os alunos avaliam de forma positiva o uso dos aparelhos móveis para fins educativos, enquanto aos professores, identificamos dois posicionamentos, professores que acreditam a viabilidade do uso do celular no ensino médio e professores que pensam o contrário.

Palavras-chave: Ensino de Ciências Exatas, Aparelho Móvel, Ensino Médio.
\end{abstract}

ABSTRACT: This paper presents a case study carried in two public schools, aiming to study the acceptability of students and teachers on the use of mobile devices in the exact sciences teaching. The schools were selected, randomly, in the city of Macapá, State of Amapá, and two structured questionnaires were applied to collect data, with three teachers and two hundred and thirty students from high school. The results showed that the students' responses converge on the use of the apparatus for educational purposes, even with some divergence. Moreover, teachers presented divergent views on the use of these tools. When comparing the data, we verified that the students think similarly about the use of cell phones for teaching, whose Student t tests presented values $p>0.05$ or $p>0.01$. Thus, regardless of the $s$ chool, students positively evaluate the use of mobile devices for educational purposes, while teachers, we identified two visions, teachers who believe the viability of using the cell phone in the high school and teachers who think otherwise.

Keywords: Exact Sciences Teaching, Cell Phone, High School.

\section{INTRODUÇÃO}

No século XXI, o mundo deu um longo avanço no seu contexto tecnológico e fez com que milhares de pessoas adquiram diversos aparelhos de alta tecnologia como telefones celulares, tabletes, notebooks, netbooks, entre outros aparelhos (KALHIL; MENE-

\footnotetext{
${ }^{1}$ Licenciado em Física pela Universidade Federal do Amapá, e-mail: jsmedeiros1@hotmail.com.

${ }^{2}$ Doutor em física pela Pontifícia Universidade Católica do Rio de Janeiro, professor adjunto da Universidade Federal do Amazonas, Departamento de Física, pesquisador dos Grupos de Nanotecnologia em Produtos Naturais e Pesquisa em Materiais, email: hdffilho@ufam.edu.br.

${ }^{3}$ Mestre em Ciências Farmacêuticas pela Universidade Federal do Amapá, professor assistente da Universidade Federal do Amapá, Departamento de Ciências Exatas e Tecnológicas, Curso de Especialização em Ensino de Física, líder do Grupo de Pesquisa Materiais Amazônicos, e-mail: robert_fisic@unifap.br.
} 
ZES, 2008).

Esses aparelhos, em geral, têm acesso à internet e fazem com que as pessoas de alguma forma estejam inseridas em alguma rede social. Um dos principais fatores para essa disseminação é a funcionalidade do celular (VIVIAM; PAULY, 2012), e não para por aí, pois a cada dia essa tecnologia vem sofrendo mudanças.

Ela está mudando sem que se possa saber aonde vai parar, somando-se com o seu baixo valor comercial do celular, que o transforma numa ferramenta muito popular (SILVA; CONSOLO, 2013). Os maiores consumidores desta tecnologia são os jovens, que agregam essa tecnologia a sala de aula; o que não se sabe e se é exclusivamente num contexto de entretenimento ou também educativo. Desta forma, a utilização dos apareIhos de comunicação alterou o cotidiano nas escolas (BENTO, 2013).

Um dos principais fatores dos estudantes terem aversão às ciências exatas é que geralmente são disciplinas complexas, com sistemas de medidas e valores matemáticos muito mais discutidos do que os próprios fenômenos em si (SILVA; DAMASIO, 2013), e ensinar física, química ou matemática sem matemática é uma tarefa muito complexa, quase impossível. Mas, os meios tecnológicos poderiam acabar com essa aversão? Acabar seria uma palavra muito subjetiva, mas talvez amenizar esta problemática já seria um grande avanço, considerando que os benefícios da tecnologia na educação associamse ao estímulo à criação e investigação de conhecimento, o que permite melhor compreensão do aprendizado da matemática no contexto do ensino de ciências (SENA; BURGOS, 2010).

Entender uma equação matemática que o professor deduz no quadro é uma coisa e associar essa equação com a vida do aluno é outra. O ensino de ensino de física, química e da própria matemática acontece através da memorização de fórmulas (RAMOS; STRUCHINER, 2009), entretanto, o método da resolução de problemas não garante a aprendizagem do aluno.

No contexto do ensino, vale lembrar das tecnologias educativas e inclusive dos websites como um recurso de apoio ao professor, desde que a escola tenha acesso à internet e laboratório de informática, com computadores. Assim, há de se considerar que "é preciso fazer reservas com antecedência, o espaço e número de máquinas não é compatível para uma turma toda e, além disso, os velhos problemas permanecem como máquinas sem manutenção e um sistema mal dimensionado" (COSTA et al., 2012, p. 3421).

O celular tem vários aplicativos, como calculadoras, conversores de medidas e experimentos virtuais. As tecnologias da informação e comunicação (TIC's) proporcionam mais tempo para o aluno tirar vantagem da atividade, bem como planejar e agir na realização de um experimento (VIEIRA, 2013).

Um dos pontos positivos da utilização das TIC's é que atrai a atenção dos jovens que estão sempre em frente do computador fazendo várias tarefas, como jogar online ou nas redes sociais (ISMAIL, et al., 2013), embora quase sempre deixem o estudo de lado (ROSA; ROSA, 2005) por isso. A formação do professor tem relação com a sua ma- 
neira de ver as novas estratégias de ensino, e as pesquisas estão sendo fortemente influenciadas pelas tecnologias (RAMOS; STRUCHINER, 2009), como na área do ensino de ciências

Além disso, os aparelhos celulares são mais baratos e maioria dos estudantes o possuem, diferentemente do computador. Contudo, nem todos são a favor da implementação de aparelhos celulares no ensino de física. Um risco que a tecnologia pode trazer à educação é a dependência, pois os jovens sabem como funcionam as tecnologias, mas a globalização disseminou este conhecimento. Além disso, eles não sabem calcular simples operações matemáticas em calculadoras (KALHIL; MENEZES, 2008).

Por muito tempo, o ensino de ciências nas escolas foi baseado nos livros e raras vezes em experimentos, que podem ser reais ou simulados em computadores. Para mudar essa realidade, as instituições que trabalham com a formação de professores de Física, Química e Matemática devem criar condições para o futuro educador agir em sala de aula (CACEPE, 2010).

Uma das novas maneiras do professor inovar no ensino é incluindo os celulares como parte do recurso didático na sala de aula. Por isso, o objetivo desta pesquisa foi estudar a aceitabilidade dos alunos e professores com relação ao uso de aparelhos celulares no ensino ciências exatas.

Os autores citados como parte do suporte teórico deste estudo, apresentam diferentes vantagens e desvantagens com relação ao emprego dos celulares na sala de aula, bem como Costa et al (2012), Bento e Cavalcante (2013), mas nenhum analisou a questão a partir de um estudo comparativo entre duas escolas, o que diferencia e agrega valor ao resultado desta pesquisa.

\section{MÉTODO E MATERIAL}

\subsection{Escolha das escolas e aplicação dos questionários}

Foram escolhidas duas escolas, de forma aleatória na cidade de Macapá, no Estado do Amapá, para aplicação do presente estudo, sendo uma Escola Estadual Prof. Gabriel Almeida Café - CCA, situada no bairro central e a outra Escola Estadual Nilton Balieiro Machado - NSB, situada em um bairro considerado periférico, conforme ilustra a Figura 1. 


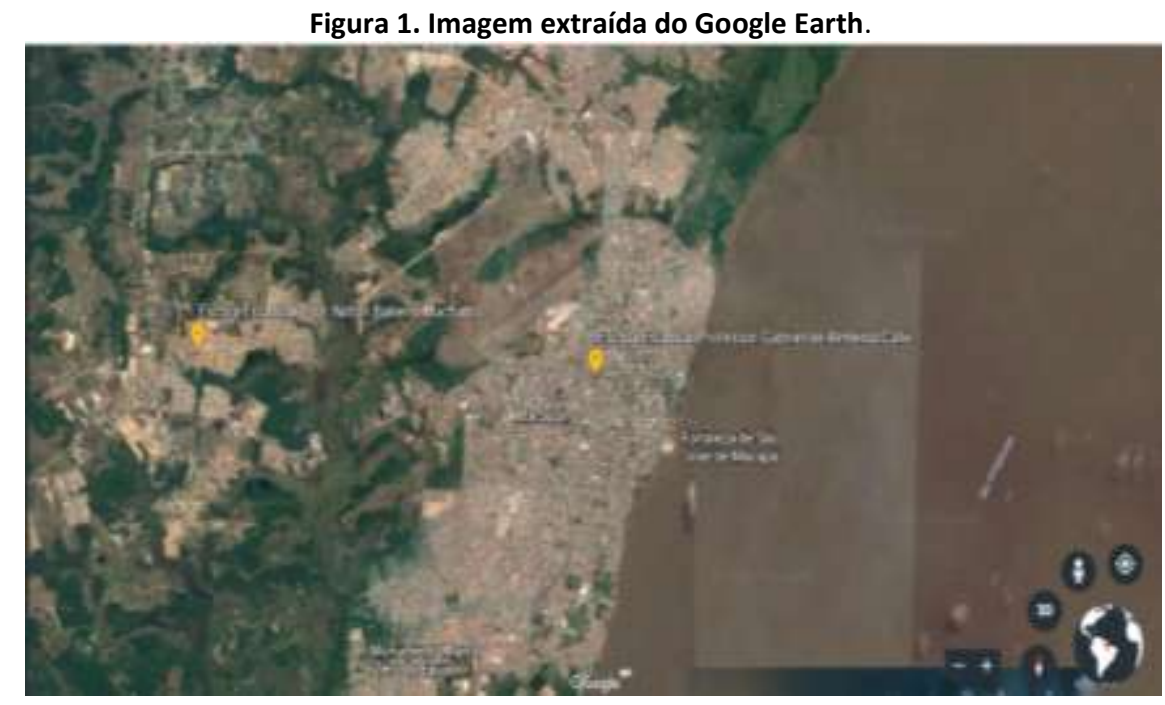

A aplicação dos questionários ocorreu durante o semestre de 2015.02. Foi realizada uma reunião com os professores das disciplinas de Ciências Exatas nas escolas pesquisadas, visando explicar o objetivo do projeto de pesquisa e sua importância para o ensino médio.

Foram elaborados dois questionários estruturados, um específico aos alunos, contendo 9 perguntas e outro aos professores, com10 perguntas, com finalidade de coletar os dados.

As perguntas dos questionários foram organizadas com alternativas direcionadas e livres. Estas foram elaboradas com base em estudos com foco no uso de aparelhos celulares na sala de aula (COSTA et al., 2012; FLORES, 2014; RAMOS, 2012; MÜLLER et al., 2012; ROSA; ROSA, 2005).

\subsection{0 método estatístico}

O método estatístico aplica-se em pesquisa que se deseja comparar os dados coletados ou para expor o resultado do fenômeno através de exposição gráfica ou tabular. Nesta pesquisa optamos pela aplicação do Teste T de Student para realizar análise das respostas de 230 estudantes do ensino médio, comparando as médias das respostas mais frequentes do Questionário $A$.

$O$ teste $t$ de Student aplicou-se para verificar se há existência de diferença significativa entre as médias de duas amostras (MORETTIN; BUSSAB, 2014). Também na análise das duas amostras independentes desta pesquisa, utilizamos as ferramentas do RStudio Software (2015), version 0.99.441.

As hipóteses do estudo foram:

- Hipótese nula - Não há diferença significativa entre as médias de respostas obtidas nas duas escolas;

- Hipótese alternativa - Há diferença significativa entre as médias de respostas nas duas escolas. 
Assim, o teste T aplicou-se para medir a probabilidade da média da amostra " $\bar{x}$ " ou algo mais extremo, dada a média da população " $\mu_{0}$ ". Então, se $\bar{x} \leq \mu_{0}$, a hipótese nula é verdadeira e se $\bar{x}>\mu_{0}$, a hipótese alternativa é verdadeira.

De acordo com Ayres et al (2003) a equação para o cálculo da estatística é dada por:

$$
t=\frac{\bar{x}-\mu_{0}}{\frac{s}{\sqrt{n}}},
$$

Na referida equação, as variáveis quantitativas "s" e " $n$ ", respectivamente, representam o desvio padrão da amostra e o tamanho da amostra.

Para as respostas do segundo grupo de participantes deste estudo, realizou-se análise qualitativa na discussão dos resultados, pois participaram apenas 3 professores, quantitativo que não é suficiente para uma análise estatística. Mesmo assim, considerou-se importante estudar as informações que os profissionais da educação disponibilizaram ao responder o Questionário $\mathrm{B}$.

\section{DISCUSSÃO DOS RESULTADOS}

\subsection{Aceitabilidade dos alunos com relação ao uso do celular na escola}

Com base nos dados coletados, constatou-se que 83,2\% dos 230 alunos têm um ou mais aparelhos telefônicos, contra $16,8 \%$ que não possuía nenhum aparelho. Esse resultado se aproxima muito com o estudo de Costa et al. (2012), que apontou que 87\% dos alunos levavam aparelhos celulares para sala de aula, enquanto que $13 \%$ não levavam.

O estudo de Flores (2014) constatou que os aparelhos celulares podem ser considerados mais que um telefone, quando usado de forma correta em sala de aula. Por outro lado, Ramos (2012) argumenta que se deve preocupar com o uso de celulares na escola, uma vez que os alunos podem utilizá-los para entretenimento.

Foi perguntado se na disciplina de Física ou Química ou Matemática, os celulares ajudavam ou atrapalhavam. As respostas foram diversificadas, mas houve predominância para ambos os casos de alunos que acreditam que ajuda (70\%), pois é possível pesquisar na internet. Outros acreditam que atrapalha $(18,7 \%)$, pois há distração com os aplicativos. Alguns ainda acreditam que nem ajuda, nem atrapalha $(8,7 \%)$, já que usam o celular apenas para emergência.

Averiguou-se em outra pergunta se a escola deveria proibir o uso de aparelhos em sala de aula. Os alunos divergem quanto a isso, já que uns acreditam que não $(51,7 \%)$, pois os celulares ajudam como ferramenta para a pesquisa e outros que acreditam que deve haver a proibição $(48,3 \%)$ para evitar a distração no momento da aula, apontando que o uso de celulares dentro de salas de aula pela visão dos próprios alunos 
é algo controverso.

No âmbito da legislação federal, Flores (2014) destaca o Projeto de Lei no 2.246A/2007, de autoria do deputado federal, Pompeo de Mattos, que veta o uso de celulares em sala de aula. Além disso, alguns estados brasileiros não permitem sua utilização em escolas. Contudo Flores (2014) alerta que não há no âmbito deste projeto, menção a estudo que trate das vantagens do uso do aparelho em sala de aula.

No que tange a eficácia do uso do celular para a aprendizagem, os alunos em sua maioria $(95,6 \%)$ acreditam que o celular pode ser usado para armazenamento de aplicativos digitais que são úteis ao ensino e como ferramenta para pesquisa virtual. Quanto a este aspecto, não houve tanta discrepância nas escolhas das respostas do questionário, o que reforça a sua aplicabilidade no ensino de ciências exatas.

Quando perguntados se o celular, através dos aplicativos pode ajudar no ensino de Física, Química ou Matemática, novamente percebemos a grande divisão que há entre as percepções deste grupo de alunos. Muitos pensam que os aplicativos ajudam $(54,3 \%)$, outros que os aplicativos de entretenimento escravizam os usuários (41,7\%), o que também foi de certa forma verificado por Costa et al., (2012) que mostraram que os alunos usam mais o celular para receber e enviar mensagens ou ouvir música.

Por outro lado, quando questionados como as redes sociais podem interferir no contexto do ensino de Física ou Química ou Matemática, a maioria dos alunos (82,2\%) destacaram que a interação em tempo real pode ser útil neste processo de ensino.

No ensino destas disciplinas, vale lembrar que existem muito métodos e técnicas para aplicar em sala de aula, como por exemplo, o "Peer Instructions" que é uma técnica americana de ensino que se baseia na ajuda mutua entre alunos e que pode aplicar-se nas redes sociais (MÜLLER et al., 2012).

Ainda com relação aos dados coletados, (62,2\%) acreditam que celulares caros possuem mais recursos e por isso podem ajudar os alunos que tem mais condições financeiras. Enquanto que $(37,8 \%)$ acreditam que independente de marca ou modelo do celular, estes também possuem ferramentas auxiliam no ensino.

Os dados nos levam a refletir que uma parte dos alunos que participaram do estudo, acreditam que por possuir aparelhos mais sofisticados, eles aprendem mais do que os alunos que não tem. Contudo, há de se considerar que no ensino da Física, Química e Matemática é possível a utilização de softwares educativos de baixo custo ou livres disponíveis na internet, que podem ser instalados em qualquer aparelho móvel.

Por último, foi perguntado aos alunos se a Wifi pode ajudar no ensino de Física ou Química ou Matemática. Neste caso, (71,7\%) acreditam que o aluno conectado à internet na hora da aula pode tirar dúvidas pontuais ora não tiradas pelo professor. Alguns $(19,6 \%)$ apontam que o conhecimento da internet nem sempre é confiável. E uma parcela reduzida $(6,9 \%)$ não usa internet para fins educacionais e outros argumentam que não entendem $(1,7 \%)$ para que usar internet na sala de aula. 


\subsection{As respostas dos alunos, segundo o Teste t de Student}

Foi realizada análise estatística com relação as repostas dos alunos escola x escola para investigar se há homogeneidade, cujos resultados de não significância estatística e de diferença entre as médias são indicados na Figura 2. Figura 2. Gráfico comparativo das médias das respostas mais frequentes
das alternativas de todas as perguntas respondidas pelos alunos.

Teste $T$ para as duas amostras independentes
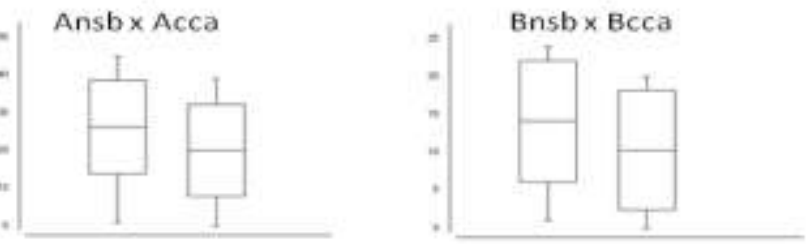

Cnsb $\times$ Ccca

Dnsb $\times$ Deca
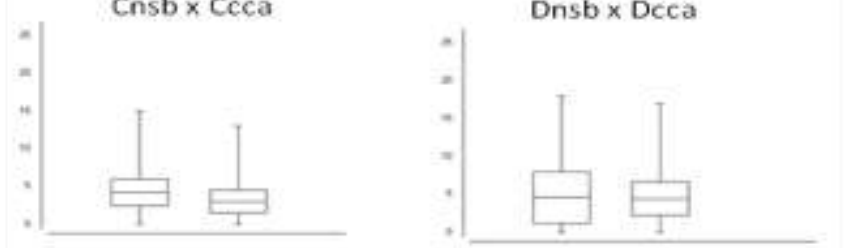

Ensb $\times$ Ecca

$A, B n s b \times A, B c c a$
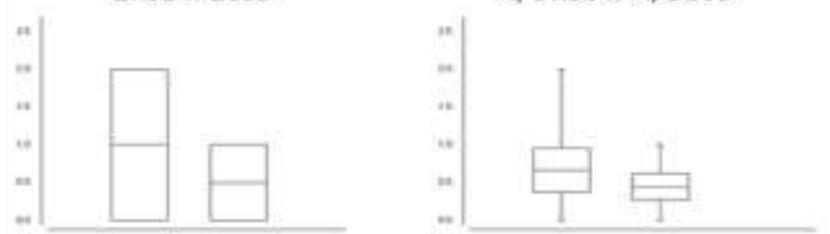

A, Cnsb $\times$ A, Ccca

A, Dnsb $\times$ A, Dcca
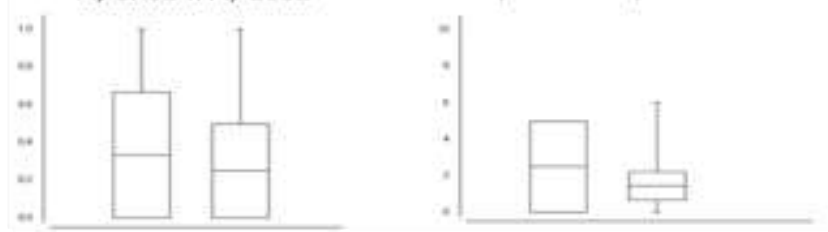

Os dados estatísticos mostram que os alunos de ambas as escolas pensam de forma semelhante para as alternativas de $A$ até $E$, com $T=1.0739$ onde $p=0.2839$ para os alunos que marcaram a alternativa $A$ em ambos os casos, $T=1.0072$ onde $p=0.2617$ para os alunos que marcaram a alternativa $B, T=0.5295$ onde $p=0.1307$ para os alunos que marcaram a alternativa $C, T=0.3221$ onde $p=0.0891$ para os alunos que marcaram a alternativa $D, T=0.2644$ onde $p=0.0789$ para os alunos que marcaram a alternativa $E$, $T=0.6576$ onde $p=0.1608$ para os alunos que marcaram as alternativas $A$ e $B$, respectivamente, $T=0.00$ onde $p=0.0298$ para os alunos que marcaram as alternativas $A$ e $C$, respectivamente, $T=0.00$ onde $p=0.0377$ para os alunos que marcaram as alternativas $A$ e $D$, respectivamente.

Os demais resultados apresentaram, assim como acima mencionado nos princi- 
pais resultados, pouca dispersão, apresentando homocedasticidade, ou seja, são todos homogeneamente próximos uns dos outros. A saber, tem-se: $C$, Dnsb $\times C$, Dcca obteve $t=$ $0.4472, C$, Ensb $\times$ C, Ecca obteve $t=-1.000$, D, Ensb $\times$ D, Ecca obteve $t=-0.8220, A, B$, Dnsb $\times A, B$, Dcca obteve $t=-4472, A, B$, Ensb $x A, B$, Ecca obteve $t=1.000$ (apresentou heterocedasticidade), $A, D$, Ensb $\times A, D$, Ecca obteve $t=1.000$ (apresentou heterocedasticidade), $A, C$, Dnsb x A, C, Dcca obteve $t=1.000$ (apresentou heterocedasticidade), A, B, C, Dnsb $x$ $A, B, C$, Dcca obteve $t=-1.000$ (apresentou heterocedasticidade), NqRnsb x NqRcca obteve $\mathrm{t}=-0.6030$ (apresentou heterocedasticidade).

Os resultados que apresentaram heterocedasticidade, todos são menos expressivos e que representam a pequena parcela de alunos que ou não quiseram responder ou apresentaram respostas singulares em relação aos demais alunos. Logo, conclui-se que os testes estatísticos apresentaram valores acima de $p>0.05$ ou $p>0.01$.

Em outras palavras, tanto os alunos da Escola Estadual Nilton Balieiro Machado, quanto da Escola Estadual Gabriel de Almeida Café pensam de forma semelhante, quanto a finalidade e ao uso do celular na sala de aula ou não há diferença significativa em relação as alternativas escolhidas pelos alunos do questionário $A$.

\subsection{As respostas dos professores de ciências exatas}

Conhecer o ponto de vista do professor é muito importante, porque ele é quem está mais próximo da construção de conhecimento dos alunos, quando se fala em processo de ensino (ROSA; ROSA, 2005).

Os três professores que participaram deste estudo, quando questionados sobre o tempo de docência responderam que trabalham mais de 5 com ensino de Física, Química e Matemática (PROFESSOR A; PROFESSOR B; PROFESSOR C), dado semelhante a pesquisa de Bento e Cavalcante (2013), cujos os professores tinham experiência de ensino de 5 a 20 anos. Isso mostra que os professores possuem uma grande experiência e que os problemas referentes ao ensino não devem estar ligados à falta de experiência e sim a falta de coordenação entre a escola, alunos e os próprios professores, conforme argumenta Ramos (2012).

Por outro lado, foi perguntado sobre as principais dificuldades dos alunos. Os professores $A, B$ e $C$ responderam que dificuldades são a pouca noção de matemática bási$\mathrm{ca}$, conversas paralelas e as redes sociais que os alunos conectam pelo celular causam as notas baixas e mau rendimento escolar.

Também foi questionado, especificamente, se os aparelhos celulares ajudam ou atrapalham a aprendizagem do corpo discente. Os professores A e B responderam que devido os celulares estarem conectados à internet, podem ajudar a resolver dúvidas pontuais dos alunos e o professor $\mathrm{C}$ respondeu que atrapalha, pois há distração.

Estes dados indicam que alguns professores de ciências exatas acreditam na aplicabilidade dos celulares no ensino. Enquanto que outros, não, cujas respostas foram equivalentes ao corpo discente, uma vez que, as manifestações a este respeito não foram 
unânimes.

Averiguou-se também outro aspecto, quanto ao uso do celular no ensino. $O$ fato de que o professor $C$ avalia que se na escola for permitido o uso do celular, há necessidade de ter controle. Já os professores A e B compreendem que pode ser positivo o seu uso na sala de aula, se o celular ter acesso à internet, pois enriquece as aulas de ciências exatas ou que celular só servem para entretenimento e comunicação.

Percebe-se aqui diferentes interpretações e ideias, o que torna acirrado o debate sobre o uso dos aparelhos móveis em sala de aula. Essa questão se acentua quando, consideramos o fato de que alguns alunos possuem celulares mais sofisticados que os demais, pois estes podem ter melhores aplicativos e podem interagir mais, embora outro mencione que não há diferença, pois no ambiente escolar, a classe social e o poder aquisitivo não importam (PROFESSOR A; PROFESSOR B; PROFESSOR C).

$O$ professor $B$ comentou em sua resposta que se o acesso à internet via computadores pode substituir o uso do celular, que se de fato ocorrer, não haveria mais a necessidade de uso dos celulares na escola. Enquanto que os professores A acredita que continuaria o uso para fins de entretenimento e o professor $C$ expressou que as mídias devem ser inseridas no contexto do ensino como um recurso tecnológico.

Ademais, foi perguntado se o uso de aplicativos de celular auxilia os alunos. A este respeito, os professores $A$ e $B$ responderam que sim, pois aumenta a velocidade de resposta do aluno. Já o professor $C$ não é a favor do uso dos aplicativos na sala de aula, como calculadores e conversores.

Há de se considerar que, as respostas diferentes, quanto a presença de aplicativos no ensino, pode estar relacionada à falta de conhecimento sobre os reais benefícios dos aplicativos ao desenvolvimento cognitivo do aluno, uma vez que os celulares do futuro serão inteligentes e ajudarão no processo de ensino (YAN et al., 2015).

Quando questionados sobre como ensinar os alunos acostumados com as tecnologias, as respostas foram unânimes. Os professores $A, B$ e $C$ relataram que necessitam de formação continuada sobre metodologias de ensino para se adequar a realidade do aluno. Portanto, estas respostas indicam que os professores de ciências exatas ainda precisam atualiza-se em metodologias que envolvam as tecnologias.

Os professores também expressaram de forma unânime que a escola não deve se intrometer no trabalho do professor e na gestão das mídias, pois é o professor quem está mais próximo do aluno (PROFESSOR A; PROFESSOR B; PROFESSOR C). Concordamos com a manifestação dos professores que participaram da pesquisa, desde que o corpo docente, conte com o apoio e acompanhamento da coordenação pedagógica.

Por fim, os professores foram questionados sobre a funcionalidade dos telefones. Com relação a este aspecto do questionário, os professores divergiram quanto suas utilidades, uma vez que o professor A e C acreditam que tanto computador como celular podem ser usados no ensino de ciências exatas. Por outro lado, o professor $B$ entende que os celulares são de mais fácil manipulação, o que leva os alunos o transformarem em um brinquedo. 


\section{CONCLUSÃO}

Neste estudo centrou-se em analisar aceitabilidade com relação ao uso de apareIhos celulares no ensino ciências exatas, por alunos e professores de duas escolas públicas. Os resultados mostraram que $82,3 \%$ dos estudantes têm celular e que usam os seus aplicativos para fins educativos, como a calculadora digital para resolver cálculos.

Além disso, outros estudantes posicionaram-se contra o uso do celular em sala de aula, justificando que este recurso tecnológico atrapalha o processo de ensino, o que demonstrou um pensamento divergente entre os estudantes do ensino médio.

Ademais, estaticamente verificou-se que não houve dispersão nas repostas dos alunos, quando comparadas as suas respostas, o que significa que os estudantes de ambas as escolas pensam de forma semelhante, embora consideremos a subjetividade de algumas posições contrárias.

Já os professores manifestaram de forma divergente em relação ao uso dos apareIhos móveis no ensino de ciências exatas na sala de aula, já que suas respostas variaram entre aqueles que acreditam que é viável a sua utilização na escola e outros não. Assim, o resultado da pesquisa indica que professor deve atentar às inovações tecnológicas como parte das metodologias de ensino e adequar-se à sua aplicação no contexto escolar.

\section{REFERÊNCIAS}

AYRES, M. et. al. Biostat 3.0: Aplicações estatísticas nas áreas das ciências biológicas e médicas. Belém: Sociedade Civil de Mamirauá, 2003.

BENTO, M. C. M; CAVALCANTE, R. S. Tecnologias Móveis em Educação: o uso do celular na sala de aula, Educação, Cultura e Comunicação, São Paulo, v. 4, n. 7, p.113-120, Jan./Jul. 2013.

CAPECE, J. A. Fundamentos teóricos da ditáctica de física: algumas reflexões a partir da prática docente. Revista de Filosofia, Amargosa, v.2, n. 2, p. 63-73, 2010.

COSTA, J. F. et. al. O celular e o ensino de ondas na escola: uma proposta preliminar. Atas do II Congresso Internacional TIC e Educação. Lisboa: Universidade de Lisboa, 2012. p. 3420-3437.

FLÔRES, C. A utilização do aparelho celular em sala de aula. In: XIV Congresso Internacional de Relações Públicas e Comunicação. Salvador: ALARP, 2014.

ISMAIL, I. et. al. Teaching via mobile phone: A case study on Malaysian teachers' technology acceptance and readiness. Journal of Educators Online, Phoenix, v. 10, n. 1, p. 138, Jan. 2013.

KALHIL, J. B; MENEZES, A. P. S. Os desafios do ensino de física e ciências na Amazônia ante às TIC's. Lat. Am. J. Phys. Educ., Buenos Aires, v. 2, n. 3, p. 228-232, 2008. 
MORETTIN, P. A; BUSSAB, W. O. Estatística Básica. 6. ed. São Paulo: Saraiva, 2014.

MÜLLER, M. G. et. al. A. Implementação do método de ensino peer Instruction com o auxílio dos computadores. Do projeto "uca" em aulas de física do ensino médio. Cad. Bras. Ens. Fís., São Paulo, v. 29, n. Especial 1, p. 491-524, Set. 2012.

RAMOS, M. R. V. O uso de tecnologias em sala de aula. Revista Eletrônica: LENPES-PIBID de Ciências Sociais-UEL. Londrina, v. 1, n. 2, p. 1-16, 2012.

RAMOS, P.; STRUCHINER, M. Analysis of the conceptions of education in research on the development of computer-based materials in science and health education. Ciência \& Educação (Bauru), São Paulo, v. 15, n. 3, p. 659-679, 2009.

ROSA, C. W.; ROSA, A. B. Ensino de Física: objetivos e imposições no Ensino Médio. Revista Electrónica de Enseñanza de las Ciencias, Vigo, v. 4, n 1, p. 1-18, 2005.

SENA, D; BURGOS, T. O computador e o telefone celular no processo ensinoaprendizagem da educação física escolar. In: Anais do 30 Simpósio Hipertexto e Tecnologia da Educação. Recife: UFPE, 2010.

SILVA, D. R; DAMASIO, F. Aplicativos de celular como organizadores prévios para unidades de ensino potencialmente significativas na educação básica de física. Revista Eletrônica Técnico-Científica do IFSC, Florianópolis, v. 2, n.1. p. 788, Edição Especial II SICT SUL, 2013.

SILVA, M. G. M; CONSOLO, A. T. Uso de dispositivos móveis na educação - o SMS como auxiliar na mediação pedagógica de cursos a distância. 2007. Disponível em: http://arquivos.info.ufrn.br/arquivos/20131932065b4717513331e763c47b13f/Dispos itivos_moveis.pdf, Acesso: 03/12/2018.

VIEIRA, L. P. Experimentos de Física com Tablets e Smartphones. (Dissertação de Mestrado). Universidade Federal do Rio de Janeiro. Rio de Janeiro, 2013.

VIVIAN, C. D; PAULY, E. L. O uso do celular como recurso pedagógico na construção de um documentário intitulado: fala sério! Revista Digital da CVA, São Paulo, v. 7, n. 27, p. 1-12, 2012.

YAN, L. et. al. Research and application of mobile teaching based on smart phone in application-oriented specialty. Experimental Technology and Management, Oriprobe, v. 32, n. 10, p. 83-86, 2015.

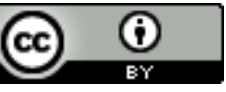

License information: This is an open-access article distributed under the terms of the Creative Commons Attribution License, which permits unrestricted use, distribution, and reproduction in any medium, provided the original work is properly cited.

Article received on June 04, 2018.

Accepted on October 25, 2018. 